\title{
Effective coastal adaptation needs accurate hazard assessment: a case study in Port Resolution, Tanna Island Vanuatu
}

\author{
Gaelle Faivre $^{1,2}$ (D) $\cdot$ Rodger Tomlinson $^{1} \cdot$ Daniel Ware $^{1,2} \cdot$ Saeed Shaeri ${ }^{3} \cdot$ \\ Wade Hadwen ${ }^{2} \cdot$ Andrew Buckwell $^{2}$ - Brendan Mackey ${ }^{2}$
}

Received: 22 June 2021 / Accepted: 28 December 2021 / Published online: 17 January 2022

(c) The Author(s) 2022

\begin{abstract}
Developing countries face risks from coastal hazards that are being amplified by climate change. The selection of effective adaptation interventions to manage these risks requires a sufficiently accurate assessment of the coastal hazard at a given location. Yet challenges remain in terms of understanding local coastal risks given the coarseness of global wave models and the paucity of locally scaled data in most developing countries, including Small Island Developing States (SIDS) like Vanuatu. This paper aims to examine the differences in hazard assessment and adaptation option selections arising from analyses using globally versus locally scaled data on coastal processes. As a case study, we focused on an eroding cliff face in Port Resolution on Tanna Island, Vanuatu, which is of concern to the local community and government authorities. The coastal process modeling revealed that the global wave data generated unrealistically high predictions of wave height within Port Resolution Bay. Expensive engineering adaptations designed to provide coastal protection were therefore likely to fail in preventing ongoing cliff erosion. In this case, the best adaptation solution involves changing land use to revegetate and help stabilize the cliff top. Our case study highlights the importance of accurate hazard assessment, especially in data-poor regions where the extrapolation of global datasets and models in the absence of local data can result in poor adaptation decision-making. Furthermore, the multidisciplinary approach applied here can be applied in other data-poor regions to strengthen analyses exploring the benefits of local adaptation interventions.
\end{abstract}

Keywords Coastal hazards $\cdot$ Climate change adaptation $\cdot$ Cost-benefit analysis $\cdot$ Numerical modeling $\cdot$ SIDS $\cdot$ Vanuatu

Gaelle Faivre

g.faivre@griffith.edu.au

1 Coastal and Marine Research Centre, Griffith University, Gold Coast, Australia

2 Griffith Climate Change Response Program, Griffith University, Gold Coast, Australia

3 CSU Engineering, Charles Sturt University, Bathurst, Australia 


\section{Introduction}

Small Island Developing States (SIDS) have a long history of resilience and adaptation to environmental variability but remain among the most vulnerable countries to the manifest impacts of anthropogenic climate change, including natural disasters (Barnett and Campbell 2010). Most SIDS rural communities are subsistence-based, and therefore human well-being is directly related to ecosystem service (ES) delivery, which is affected by these impacts, which if not mitigated, risk food insecurity and malnutrition (Buckwell et al. 2019). Further challenges arise from the fact that homes, gardens, buildings, roads, and latterly major infrastructure (schools, hospitals, and airports) are located on the coastline and are therefore exposed to coastal hazards, such as coastal erosion, inundation, and shoreline recession (Piggott-McKellar et al. 2020), particularly as the intensity of weather events, such as tropical cyclones, increases (Oppenheimer et al. 2019). SIDS communities face barriers to their adaptive capacity, including technical and financial resource limitations, gaps in knowledge around the extent and appropriate responses to climate change, and difficulties with implementation, including the capacity for states to manage and monitor development and investments (Donner and Webber 2014; Frankland et al. 2012; Kuruppu 2009). Many of these islands also have limited adaptive capacity to respond and recover from major events (Oppenheimer et al. 2019).

Many studies have shown that shoreline recession is mainly due to high wave energy and the consequences of increasing sea levels during extreme events. Sanford and Gao (2018) found that while wave energy could have a significant influence on erosion, many other local factors such as water levels, wind, and vegetation bordering the shoreline (mangroves, marshy shorelines, bank shorelines) are also important that require drawing upon a wide range of datasets when undertaking local coastal hazard assessments and evaluating adaptation options. While this can be more readily achieved in areas with high-quality data, there is a notable scarcity of data from developing countries and a lack of geographical balance in the literature on observed coastline changes across natural and managed systems. In addition, the Pacific Islands are often poorly represented in global analyses of risks regarding coastal processes due to an overreliance on the coarse representation of physical principles, and sometimes they can even be excluded from global analyses due to the lack of data or resolution.

Numerical models can simulate different scenarios of waves and climate to inform local risks such as erosion or flooding. However, both current and historical data are needed to build and validate these models to ensure they adequately represent reality. The absence of local data and the resulting need to rely on coarse resolution global data sets and global model outputs can result in unreliable coastal risk assessments in remote areas, which can, in turn, lead to erroneous conclusions and management interventions that fail to address risks or create new risks (Piggott-McKellar et al. 2020). While global models provide a good understanding of ocean processes in a region, regional simulations may be compromised by errors propagating from simplified boundary condition approaches. Coastal dynamics are highly defined by the local bathymetry and coastal features which could be omitted by a lack of resolution in the global models.

The study focused on Port Resolution, a coastal community on Tanna Island, Tafea Province, Vanuatu. Port Resolution already experiences coastal erosion, with an area of the embayment actively eroding (Fig. 1). However, there is limited and only coarse resolution data available on relevant physical processes. The global data for the bathymetry in Port Resolution are the ETOPO data and the Gridded Bathymetry Data (GEBCO 2019) data 
Fig. 1 Site location: Port Resolution Bay, Tanna Island, Vanuatu, and cliff erosion. Output of global wave data using WAVEWATCH3 (WW3) which is a global wave model from NOAA using the model of Tolman (2009) and rose plot of the average wave data conditions from 1979 to 2018 (image background source: ESRI Digital Globe (2018))

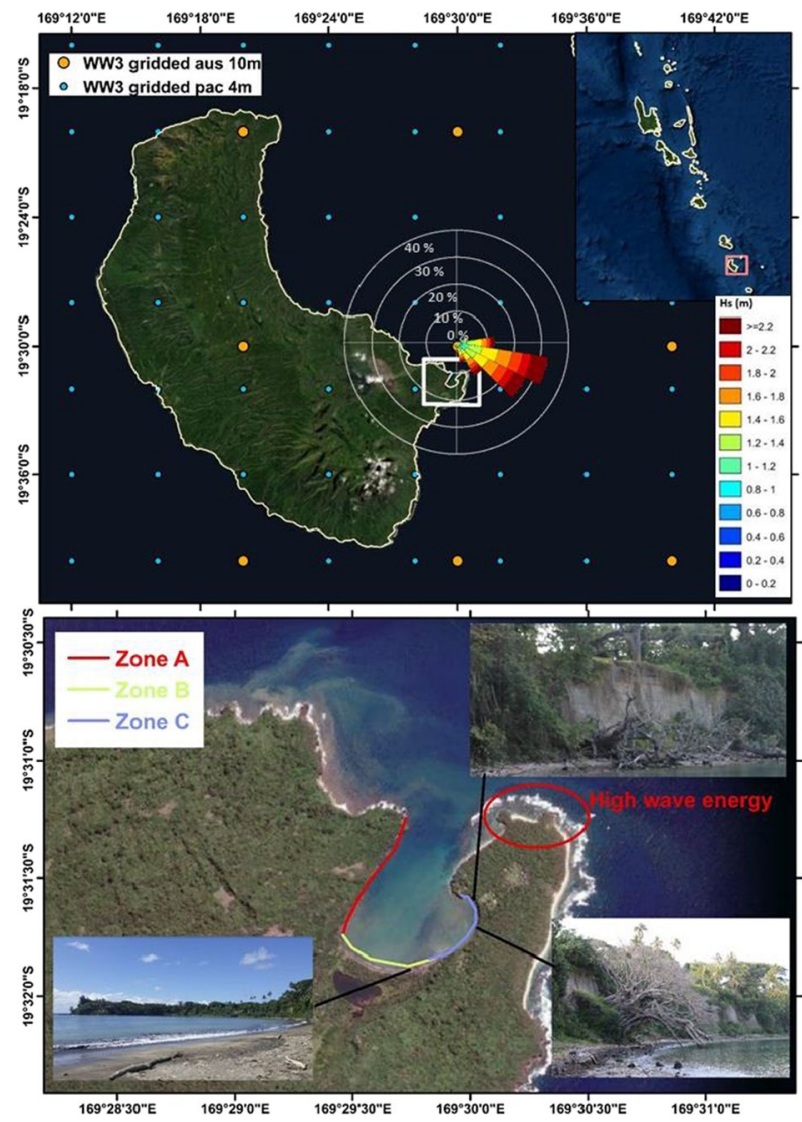

with a resolution of $\sim 900 \mathrm{~m}$ and $\sim 430 \mathrm{~m}$ resolution, respectively. GEBCO data have a resolution down to 7.5 arc second $(\sim 225 \mathrm{~m})$ in some areas of the world, but not in the South Pacific region. Global topographic data (SRTM 2020) for Vanuatu has a $90 \mathrm{~m}$ resolution, which is too coarse for adequately modeling local coastal processes.

The local context with respect to climate change threats is also important. While the IPCC reports a global sea-level rise of $3.2 \pm 0.4 \mathrm{~mm} /$ year, the rate of sea-level rise in Vanuatu is estimated at $6 \mathrm{~mm} /$ year since 1993 (IPCC 2019). Furthermore, Vanuatu, and Tanna Island in particular, has high levels of seismic activity (Chen et al. 1995) which can also impact the stability of the land and, by extension, the coastal hazard risks in Port Resolution. Thus, it is important to explore not just how wave energy dissipates across different hazard zones but also how it will be affected by sea-level projections for 2050 and 2100 . Also, the ongoing erosion of the cliff face in Port Resolution represents a serious management challenge for the local community and the provincial government.

It is widely acknowledged that people's perception of environmental risk determines both the nature and degree of their response (Adams 1995). As a result, understanding coastal hazards and shoreline risks underpins the development and implementation of well-informed, robust adaptation responses. In the case of Port Resolution, a better understanding of the local interactions between waves, tides, wind, local bathymetry, and ecosystem functioning could help to isolate the causal risk factors and identify the 
most suitable adaptation strategies. Critically, a lack of this knowledge could lead to poor decision-making which may worsen the problem particularly with climate change or shift it to another part of the system.

This paper aims to diagnose the cause of the active erosion of the cliff at Port Resolution by using a numerical model of coastal processes calibrated from globally and locally sourced data. We then sought to examine how the risks and adaptation options vary depending on the identified risk are the resolution and accuracy of the data used in the model, with consideration of the implications for adaptation decision-making throughout the Pacific and other data-scarce regions of the world in a context of sea level rising.

\section{Site description}

Vanuatu is an archipelago consisting of about 82 small islands located in the South Pacific. With $2528 \mathrm{kms}$ of coastline, it faces risks from coastal erosion and inundation exacerbated by sea-level rise. Vanuatu governance is a hybrid system with formal institutions of representative democracy combined with the integration of traditional structures. For example, village-level decision-making is done through the Nakamal, the traditional meeting place. As a case study, we focused on an eroding cliff face in Port Resolution on Tanna Island in the southern Vanuatu province of Tafea (Fig. 1). Tanna covers 58,793 ha and has a population of approximately 32,280 (Vanuatu National Statistics Office 2021(Fig. 1). The highest point on Tanna Island is Mount Tukosmera (1 $084 \mathrm{~m})$, and Mount Yasur is an active volcano located on the southeast coast. The beach at Port Resolution contains materials from volcanic origins as well as corals and shells from the offshore reef. The island's population is predominantly village-based, living in traditional housing in an agrarian subsistence-based. Tanna is often referred to as a stronghold of Kastom which refers to traditional culture, including religion, economics, art, and magic in Melanesia. The Port Resolution community comprises approximately 280 ha of land and 150 ha of inshore coastal coral reef and inshore lagoon. (Buckwell et al. 2020a, b).

Port Resolution is a pocket embayment as shown in Fig. 1. As the waves approach the shore, they bend, concentrating the wave energy on the headlands and reducing energy in the bay where sediments are deposited, via the process of divergence. Wave energy transfer to the coastline is therefore determined by the degree to which the coastline projects seaward and is thus more exposed to incoming waves and greater energies. The presence of the reef protects the shoreline from wave energy as waves initially break on the reef crest, before reforming (with less energy) across the reef flat.

Outside of major storm events, wave energy along the shoreline of Port Resolution is low all year, and the slope from the toe of the cliff to the water is mild. Port Resolution Bay is quite shallow (not deeper than $7 \mathrm{~m}$ above MSL), northeast facing, and is a normally sheltered bay $\left(\sim 2 \mathrm{~km}^{2}\right)$ on the easternmost point of Tanna Island (Brothelande et al. 2016). In March 2017, the entrance of Port Resolution was surveyed on behalf of the United Kingdom Hydrographic Office (UKHO 2017), showing the entrance to be around 6-9 $\mathrm{m}$ deep and around 500-600 m wide.

The study area was divided in 3 zones (Fig. 1) as follows:

- Zone A: The west side of the bay, around $1 \mathrm{~km}$ long, consisting of a steep rocky cliff. 
- Zone B: The only low part of Port Resolution bay, consisting of mainly sandy beach that extends from 10 to $40 \mathrm{~m}$ wide. The beach is pronounced by a shore-parallel berm that has a maximum elevation of $1.8 \mathrm{~m}$ above MSL (Brothelande et al. 2016).

- Zone C: The soft vegetated cliff, located in the southeastern part of the bay from $10 \mathrm{~m}$ around the river connected the lake to $20 \mathrm{~m}$ at the headland. A public school and houses are located around $40 \mathrm{~m}$ from the edge of the cliff. The cliff in this zone is experiencing erosion. Locals have recognized this problem for decades but reported that the rate has intensified over recent times. The erosion is now threatening the school site and an adjacent building, which is situated approximately $200 \mathrm{~m}$ from the general perimeter of the village and the road. Analysis of historical satellite images (Google Earth Pro 2020) indicates that the cliff top has moved landward by approximately $5 \mathrm{~m}$ between 2006 and 2016 and the road leading to the school is now only 15-20 m from the top of the cliff edge.

\section{Methods}

\subsection{Overview}

Our approach was based on comparing the outputs of global versus locally scaled modeled data. The global scale model was used to estimate wave height at the shoreline in the bay. The local model was also used to estimate wave height at the shoreline line in the bay but at a finer spatial resolution used for calibration (a) tidal records taken in the bay, (b) fine-scale bathymetric data, and (c) shoreline change data. The local model was also forced by the global wave height data, i.e., the "boundary conditions" of the local model were set from the global scale wave height data outside the bay. This is, in effect, a type of "downscaling." Outputs from these models were then used to estimate cliff recession due to projected sea-level rise from climate change. Shoreline change was examined in terms of shoreline erosion and recession. The methods were chosen based on our assessment of the literature and our understanding of coastal processes. Wave energy is a known major of coastal erosion and shoreline recession. We also chose our methods based on the available data and new data we were able to generate during the course of our investigations.

Based on the outputs from both models and projected shoreline hazards (erosion, recession), feasible options for adapting to the identified coastal hazards were identified. Candidate adaptations were initially selected based established on established adaptation practices in the coastal zone and then a set of feasible options selected on interpretation of the causal processes involved. A cost-benefit analysis of these feasible interventions aimed at mitigating the associated risks was undertaken (Fig. 2).

The global data used were WAVEWATCH3 (WW3) from NOAA model of Tolman (Tolman 2009). Then, a range of methods and data sources were used to account for local factors affecting coastal erosion and coastal flooding, from which a second set of adaptation options was selected. Impacts, hazards, and risks were considered under current conditions and projected climatic change. For the locally scaled assessments, three main techniques were used: theoretical engineering calculations; geographic information system (GIS); and numerical modeling. We used these techniques to analyze trends in wave climate and discerned historical coastal changes observed from satellite imagery. Benefit-cost analysis and cost-effectiveness analysis were then undertaken for the candidate adaptation options comparing the results from the global and local modeling approaches (Fig. 2). 


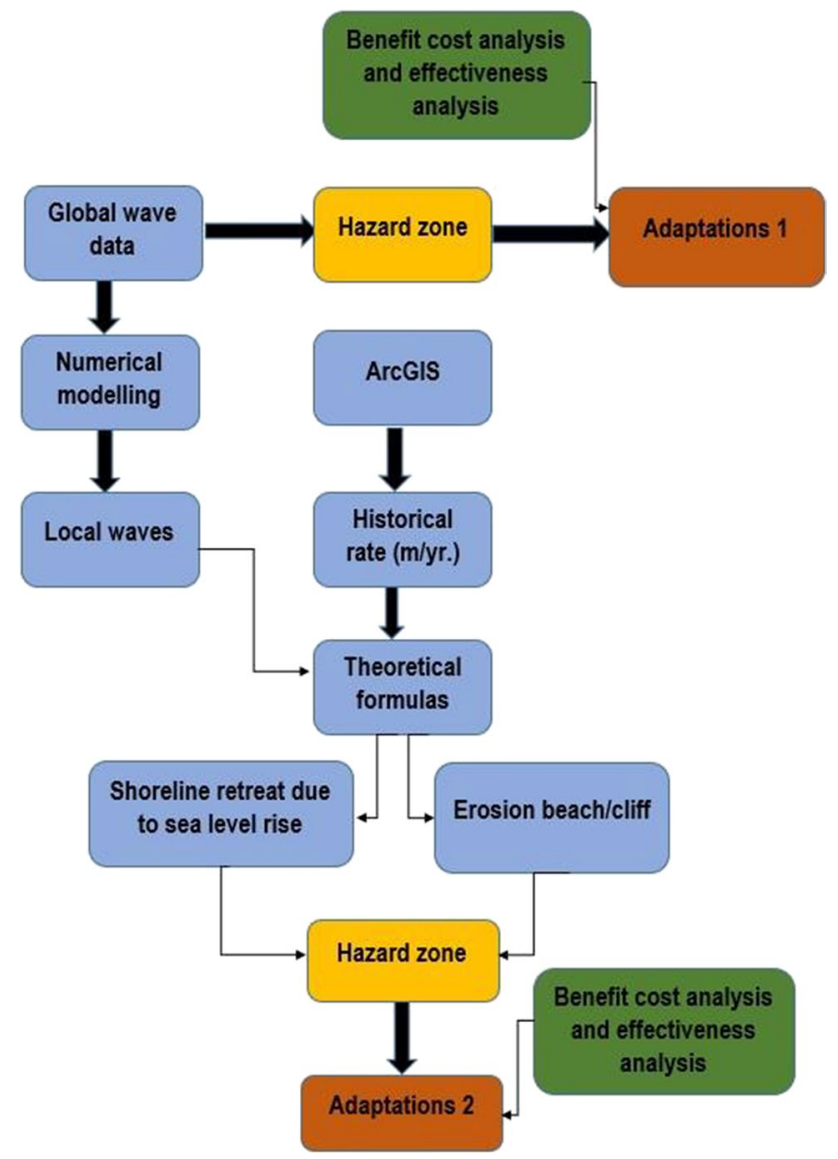

Fig. 2 An overview of the workflow used to analyze global and local scaled influences on coastal hazards at Port Resolution. Based on analysis of the global wave data alone, a set of candidate adaptation options were identified (Adaptations 1). Then, following a more complex suite of analyses that took into account local factors, another set of candidate adaptation options was selected (Adaptation 2). For both sets of adaptations, benefit-cost and effectiveness analyses were undertaken

\subsection{Wave modeling and analysis}

The impact of wave energy on the shoreline was assessed using numerical models. Wave propagation in the bay has been solved with numerical modeling using the parametric global wave model WW3 as wave boundaries. Wave energy flux was calculated and compared at different points in the bay. Changes in wave heights and wave directions were incorporated to assess the dissipation of the waves inside the Bay.

The extreme-value theory is a statistical method for quantifying the probability or return period of large events (Vitousek et al. 2017). Return periods of 1, 5, 10, 20, 50, and 100 years were calculated using WW3 wave data for the last 40 years with the significant wave height as well as the period associated for each wave.

Numerical modeling was conducted with Delft 3D (Deltares 2018) for propagating the waves inside the bay. The wave model was then coupled with the flow model and transport module. The water level was calibrated with tide data collected inside the bay between 
November 2016 and March 2017. The wave model used 3 nested grids from $150 \mathrm{~m}$ resolution down to $15 \mathrm{~m}$ resolution, the latter also being the resolution of the flow model. The model bathymetry is the best available as sourced from UK Hydrographic Office (2017), coupled with SRTM global data and data collected by Griffith University where local data were unavailable.

The surge inside the bay was calculated using Mike21 FM (DHI 2020) tropical cyclone model that extends from the latitude of $-16^{\circ}$ to $-22.5^{\circ}$ and from the longitude $165^{\circ}$ to $171^{\circ}$. It is a two-dimensional depth-integrated finite volume hydrodynamic model which uses a parametric wind field (Holland et al. 2010) to simulate surge in Vanuatu. The surge output for a case defined as the worst scenario was added to the Delft3D model during extreme events to estimate the impacts on the coast. In this case, the worst-case scenario was defined as a cyclone making landfall at Port Resolution with a central pressure of $900 \mathrm{hPa}$ (category 5) and a forward speed of $2 \mathrm{~m} \cdot \mathrm{s}^{-1}$.

\subsection{Analysis of historical changes in shoreline using global satellite date}

We examined the historical changes in shoreline changes for Port Resolution Bay based on a time series of 14 satellite image between 2006 and 2020 (Google Earth Pro 2020). Only 14 images of sufficient and useable resolution were available for the assessment of recent shoreline movement. In addition, it was found that remotely sensed scene coordinates do not coincide with a standard map projection and the coordinates of fixed point vary from image to image. To adjust for this projection challenge before extracting the shorelines, the images were corrected in ArcGIS using fix features across the period. The accuracy of the satellites images was checked using around 40 ground control points for each image. The determination of shoreline changes across time was realised using ARCGIS 10.4.1 software with the Digital Shoreline Analysis (DSAS) 4.3 extension (Himmelstoss et al. 2018). The distance from a baseline to the shoreline was calculated for 106 transects to estimate the erosion rate per year. Five zones were identified, with zones 1 and 2 included in zone B and zones 3 to 5 included in zone C (Fig. 1).

\subsection{Adaptation assessments}

We explored options from five high-level strategies for coastal adaptation in response to cliff erosion and the threats posed to the adjacent school and associated buildings (Ware et al. 2020) (Table 1). The efficacy of potential adaptation options, such as seawall construction or conservation of natural defenses (i.e., protecting fringing coral reef or avoiding dredging operations), were then reviewed based on the modeled changes in wave height and wave energy as well as the likely consequences of each action.

Cost estimates were obtained from on-site advice and from the literature review. The analysis included a risk cost computed using a standard risk formula with the consequences multiplied by the costs of failures for each year. A cost-effectiveness approach was taken, which establishes the most cost-effective option of achieving a set outcome, in this instance, the protection of at-risk assets at the end of a 15-year period. A 15-year period was selected as this reflected the original estimated rates of cliff erosion and the time period where assets would begin to be at risk. Costs include the construction cost, any reconstruction costs, maintenance costs, and the risk costs, based on three scenarios: business as usual; managed realignment of the school in year 1 and the road in year 10; and "hold the line" - engineered coastal interventions, such 
Table 1 Categories of high-level adaptation strategies for managing coastal erosion risks

1. Maintain current management approaches - Coastal processes are left to unfold in response to climatic, oceanic and vegetation conditions without any specific adaptation interventions. Coastal processes may or may not lead to continued erosion but in either case costs of construction of engineered structures are avoided. There will remain a residual risk cost, which can be quantified. The local community may eventually accept the potential loss of the impacted land (i.e., a "sacrifice zone" sensu Williams et al 2018)

2. Hold the line - In this option, engineering solutions are introduced to defend the coast when assets are considered sufficiently valuable to protect from recession of the shoreline (Williams et al. 2018). Engineering approaches either directly shore up the cliff or protect the base of the cliff from the wave energy. These engineering solutions could take the form of a seawall, an artificial reef or a beach nourishment program

3. Limited intervention - Limited intervention, or accommodation, is an approach by which adjustments are made to be able to cope with hazards, using engineered interventions to increase protection (Williams et al. 2018). For example, an artificial reef could be constructed in the embayment to accommodate sea level rise and reduce wave energy at the foot of the cliff

4. Managed realignment - This approach, also known as managed retreat (Boateng 2012) and enables the shoreline to move more naturally. Rather than relying on hard structures for defense, managed realignment depends on natural defenses to absorb or dissipate the force of waves. This approach would see community infrastructure being rebuilt further from the shoreline. A major disadvantage of this strategy is the loss of land and the expense of relocating buildings. On the other hand, this strategy has ecological benefits as it potentially allows ecosystems to adjust or migrate naturally and retain ongoing functionality (Colls et al. 2009)

5. Ecosystem-based adaptation $(E b A)-E b A$ interventions work with natural processes to make use of ecosystem services in ways that help communities adapt to the adverse effects of climate change (Colls et al. 2009). For example, a commonly deployed EbA in the coastal zone is the protection and restoration of fringing coral reefs with the ecosystem service benefit being their capacity to absorb wave energy and reduce erosion risk (Faivre et al. 2020)

as sea walls. Sensitivity analysis was carried out at discount rates of $10 \%, 15 \%, 20 \%$, and $0 \%$. No social benefits were estimated as there was only a very small area of productive land in the hazard zone.

\section{Results of coastal process analysis}

\subsection{Erosion interpretation for adaptation with global scale models}

Wave energy around Port Resolution was found to be highest during the wet season, when tropical cyclones are most prevalent. The highest wave energy is in the south of Tanna Island, where the coastline is directly exposed to the waves. Figure 1 shows a rose plot of the average global wave height data for 1979-2018 using WW3 at around $2.3 \mathrm{~km}$ from the entrance of the bay. In general, waves come from the southeast, and as a result, the Port Resolution Bay is largely protected from the waves. Inside the bay, the wave energy is very low, as the wave dissipates around the headland and across the reef flat before entering the bay. While the mean average wave height is around $2 \mathrm{~m}$ at the point displayed (Fig. 1), for the same location waves were estimated to $16 \mathrm{~m}$ during tropical cyclone (TC) Pam with the WW3 global hindcast wave model. 


\subsection{Analysis of historical changes in shoreline}

In zone 1 (transect 1 to 46 in Fig. 3a), the beach shoreline changes between -1.5 and $0.1 \mathrm{~m} /$ year, with higher erosion in the corner of the bay. In zone 2 (transect 46 to 57), sediment has accreted at rate of between 0.1 and $1.6 \mathrm{~m} /$ year. Zone 3 is quite variable, with beach erosion between transects 58 and 74 . Zone 4 features cliff erosion, at a rate of $0.27 \mathrm{~m} /$ year, between transects 76 and 100. The headland, zone 5 (transects 101 to 106), is quite stable, with some sediment coming from the bay. Short-term changes in shoreline position
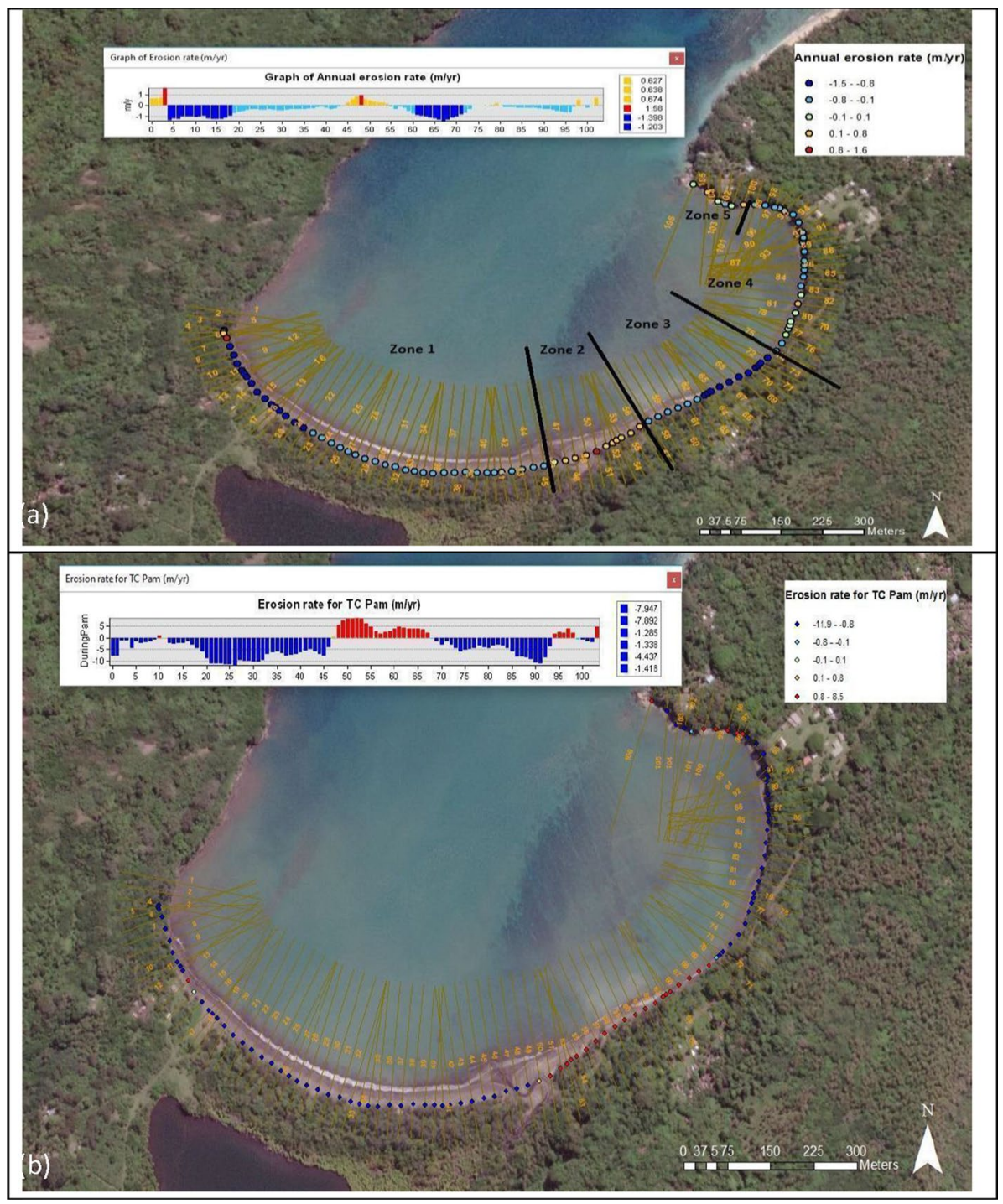

Fig. 3 Annual erosion rate using images from 2006 to 2020 (a) and short-term erosion rate using Tropical Cyclone Pam event and images from 2013 to 2015 (b) 
in response to a significant storm event were calculated using images from before TC Pam (September 2013) and after TC Pam (end of March 2015). During this period, the beach was highly eroded between transects 1 and 49 and 71 to 96, whereas sediment accumulated in between (from transect 50 to 70) (Fig. 3b). Fig. 3 illustrates that erosion is happening inside the bay, with the cliff adjacent to the road and the school (zones 3 and 4) actively eroding over the period of the study. These results suggest that erosion might be caused by high wave energy at the toe of the cliff especially during extreme wave events like tropical cyclone Pam.

\subsection{Erosion interpretation for adaptation with local scale models}

The fine resolution DELFT3D model was forced at the boundaries with the data from global model WW3, which is standard practice. The model for Port Resolution Bay was resolved and wave energy calculated during both normal wave and extreme events conditions. During normal conditions in the bay, wave energy was found to converge on the headlands, and, as a result, Port Resolution has a low energy beach inside the bay. For varying return periods $(1,5,10,20,50,100)$, wave heights inside the bay were found to be highest when waves come from the north, which is possible during cyclones. The modeled wave heights from differently sized events (ARI) and different grid resolutions (50-m grid vs $15-\mathrm{m}$ grid) at six points inside the bay were compared with global wave height offshore from WW3 in Fig. 4. The significant wave height is slightly overestimated with coarser models (1) in comparison with more detailed models (2) as shown in Fig. 4.

The wave model was coupled with the flow model, with surge included in the boundary conditions to model the significant wave height (Hs). As shown in Fig. 4, Hs is attenuated significantly inside the bay, even during a 100-year return wave event with associated storm surge. Significantly, the cliff (zone 4), where historical and recent erosion has occurred, is protected from high wave energy by the headland and the reef at the front of the cliff. Given this low wave energy at the base of the cliff during extreme wave events, cliff stability is likely to be influenced more by water levels, local currents, and the stability of the cliff substrate and soil layer at the cliff top. This finding is contrary to the expectations driven from the modeling using global model data sources,
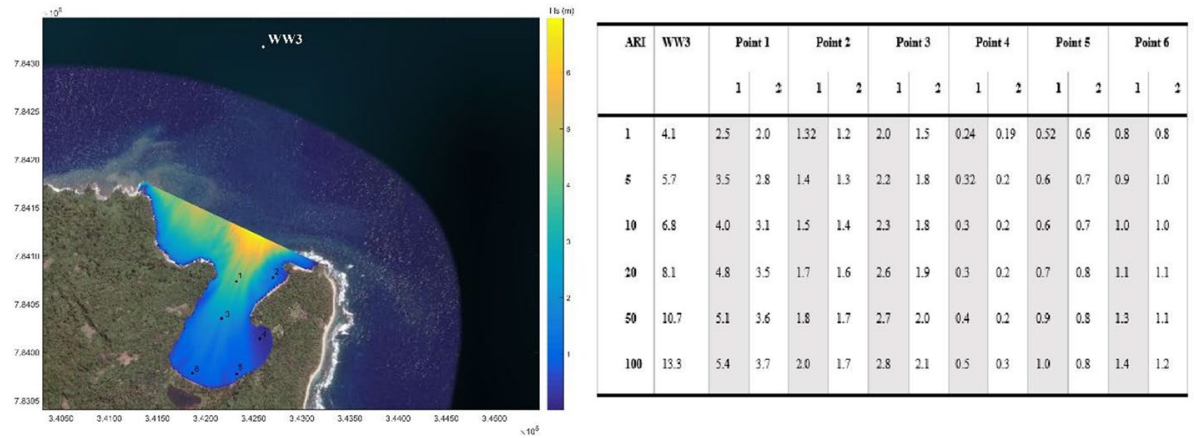

Fig. 4 Location of extraction points in the table for ARI 1, 5, 10, 20, 50, and 100 and dissipation of significant wave height for ARI100 event including 1-m surge using 15-m grid resolution (left) and significant wave height for varying ARI at WW3 location offshore and dissipated into the bay with a $50 \mathrm{~m} \times 50 \mathrm{~m}$ grid resolution model (point 1) and a $15 \mathrm{~m} \times 15 \mathrm{~m}$ grid resolution model (point 2) at the extraction point outputs (right) 
which pointed to the role of wave energy as an erosive force. Additionally, the significant wave height $(\mathrm{Hs})$ was modeled to incorporate projected sea-level rise inside the bay. The results showed that the wave energy at the coast increases with sea-level rise - owing to loss of energy dissipation over the reef - which means that sea-level rise will see current extreme wave events becoming more frequent and more shoreline damage could be expected.

Wave height is also modulated by the tide along with higher water levels. Exploring the worst-case scenario with a 100-year event and 1-m sea level rise, results showed that the wave energy increases by $17 \%$ in zone 4 , in front of the cliff, but still remains low. The higher increase in the bay is mostly on the sandy beach in zone 1, where erosion is not a source of preoccupation due to the absence of habitations. On the basis of this evidence, wave energy is likely not the main driver of the cliff erosion in zone 4. Instead, abnormally high water levels associated with higher currents, wind, and rain are likely to more strongly contribute to episodes when the cliff retreats. The adaptations to mitigate the threat should, therefore, focus on deviating the currents and stabilizing the top and toe of the cliff.

The area sensitive to the coastal erosion for the cliff of interest (zone 4) is shown in Fig. 5. This figure also shows the horizontal coastline retreat due to the possible accelerated sea-level rise. The areas susceptible to erosion of the cliff by 2100 vary from $\sim 15 \mathrm{~m}$ to $\sim 50 \mathrm{~m}$ based on variation in the historical rates of erosion for the cliff $(0.1$ to $0.4 \mathrm{~m} /$ yr). The average historical rate of change, on the basis of analyses of the available satellite imagery, is around $0.3 \mathrm{~m} /$ year. Extrapolation of this same rate of change estimates a cliff erosion zone of up to $27 \mathrm{~m}$ by 2100 . This amount of erosion would endanger the school, which is situated within the erosion perimeter of the cliff.
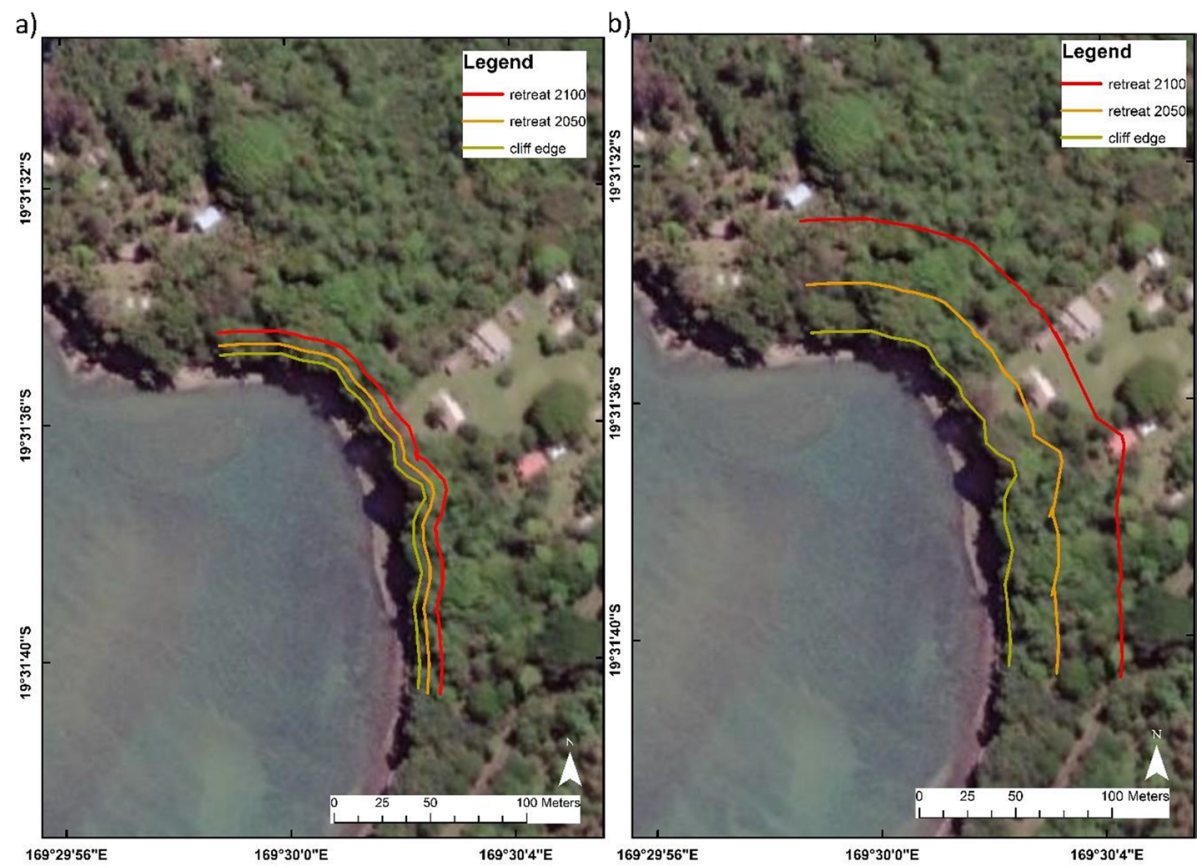

Fig. 5 Shoreline retreat in 2050 and 2100 using historical rate of $0.1 \mathrm{~m} / \mathrm{yr}(\mathbf{a})$ and $0.5 \mathrm{~m} / \mathrm{yr}$ (b) 


\section{Results from assessment of adaptation options}

We assessed the efficacy and costs of the identified set of adaptation options in relation to the hazards projected from the global and local scaled models. To assess the adaptation options, we combined strategies 3 (Limited Intervention) and 5 (EbA). We evaluated all the adaptation options detailed in Table 2. The assessment of the selected adaptation options took the form of a cost analysis taking into account design, construction, and maintenance costs, as well as their efficacy in mitigating the risk from the modeled hazard. The assessment of the efficacy of each adaption option is summarized in the second and third columns of Table 2. And, the cost analysis is presented in columns 3-6 of Table 2. We did not assess the "maintain current management approaches" strategy as it did not require any adaptation expenditures.

\subsection{Adaptation option assessment}

The assessment based on the global model suggested that high wave energy could be a contributing factor to the cliff erosion. On this basis, adaptation options are needed to protect the cliff toe from wave action to avoid destabilizing the cliff through notching and undercutting. However, the fine resolution modelling indicates that wave energy does not appear to be the main reason causing the erosion of the cliff. Rather, a mix of geotechnical factors better explain the eroding cliff face. It follows that stabilization of the top and toe of the cliff is the appropriate adaptation rather than interventions that would reduce the wave energy at the foot of the cliff. With these diverse modeling outcomes in mind, we evaluated a range of adaptation strategies and options spanning interventions that would dissipate wave energy through to those that address geotechnical factors.

\subsubsection{Hold the line}

Based on the estimates of high wave energy offshore from the global scale model data, coastal adaptations that could reduce the wave energy reaching the shoreline were reviewed. Hard engineering (capital works) options include seawalls, revetments, levees, breakwaters, and groynes (Boateng 2012). These options can be deployed to either shore up the cliff or prevent wave energy reaching the cliff toe. For example, concrete walls at the foot of the cliff would prevent erosion by reflecting the wave energy. This option "holds the line" and does not require rebuilding of the school or realignment of the road. However, these interventions are expensive, with high capital outlays and ongoing maintenance and replacement within the envelope of the period under study. Rock breakwaters have a typical design lifetime of 30-50 years with wooden groynes having a lifetime of about 10-25 years and groynes constructed with gabions of 1-5 years (Tomlinson and Jackson 2019). These structures require maintenance and have a limited lifetime - in the context of climate change adaptation, they are not long-lasting solutions. The results showed that a groyne or seawall placed at the entrance of the bay would reduce the wave energy and local currents at the toe of the cliff. Based on the global wave model alone, this adaptation option would have been chosen as the first option to mitigate the assumed instability at the toe of the cliff.

The fine-scaled numerical coastal process model showed that the waves dissipate in the embayment, and the wave energy at the toe of the cliff is low, even during a 100-year 


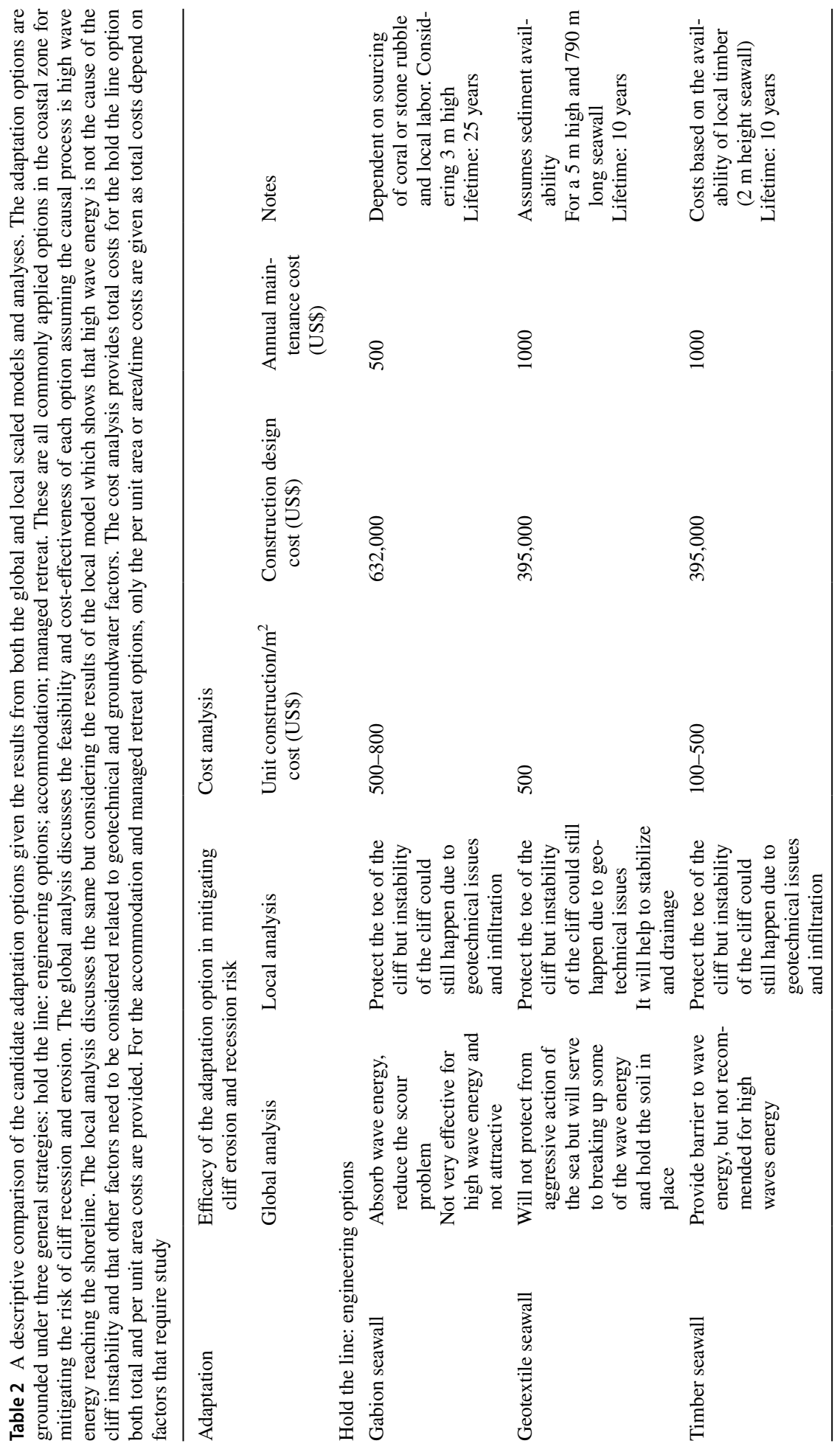




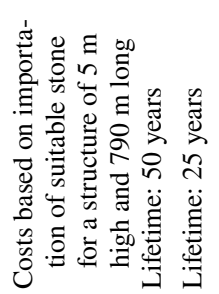

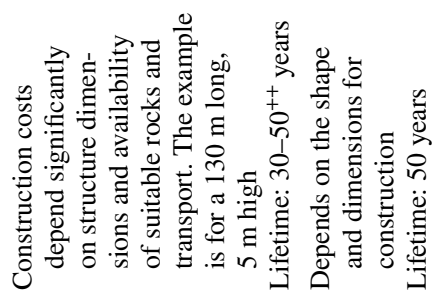

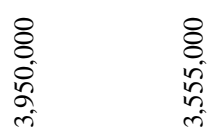

8
0
0
$\infty$
0
$=$

$\stackrel{8}{2}$

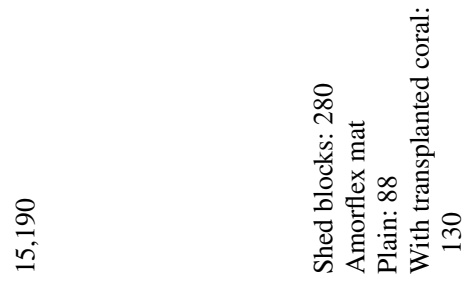

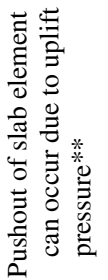

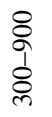

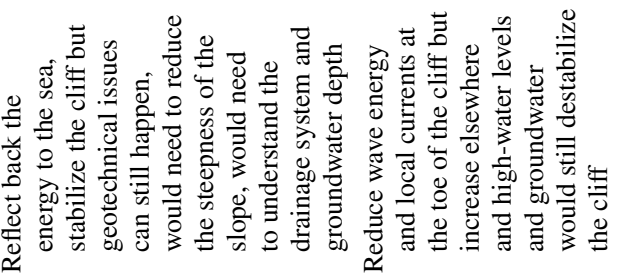

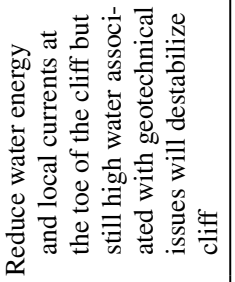

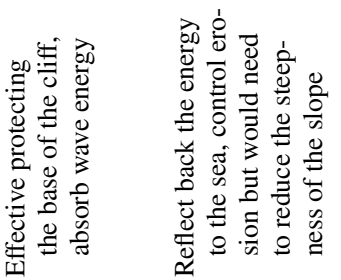

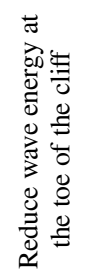

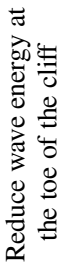

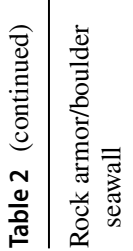

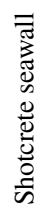

岂 

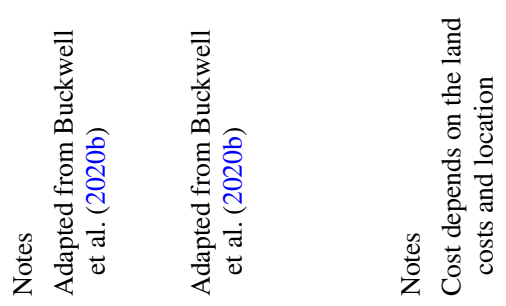

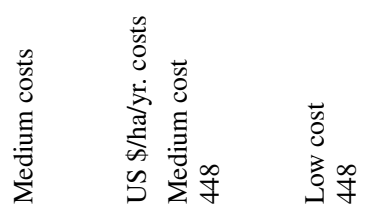

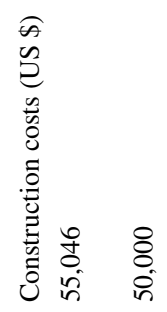

致

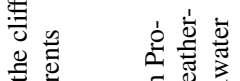

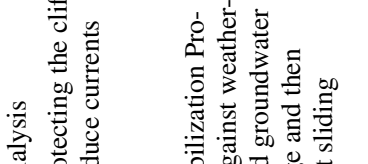

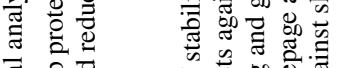

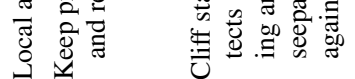

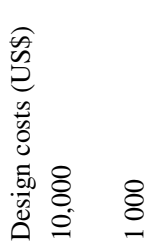

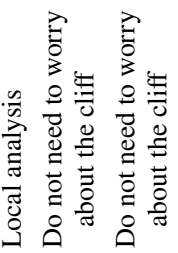

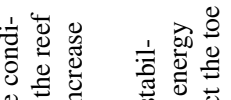

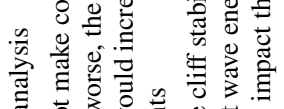

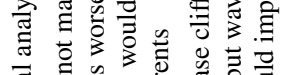

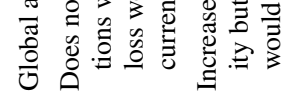

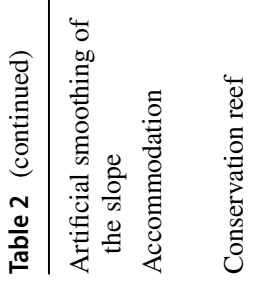
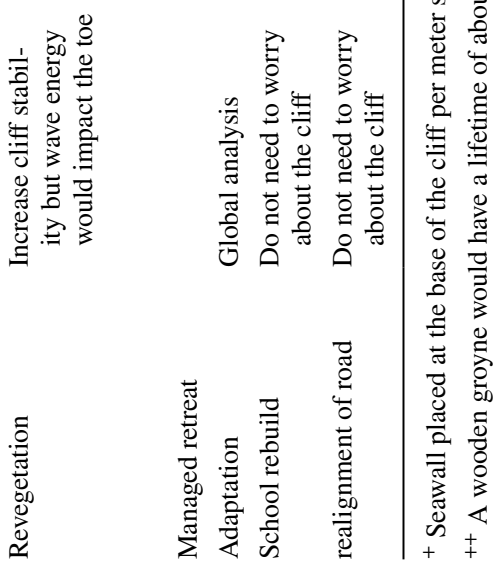
event. Reducing the wave energy reaching the toe would, therefore, not reduce the main stressors to the cliff and it would continue to erode. Port Resolution is surrounded by overhanging cliffs cut into weathered basaltic sands with a near-vertical cliff face (Brothelande et al. 2016). Cliff collapse can be due to a combination of destabilization of the cliff top from clearing the vegetation cover, groundwater pressure, and general weathering from heavy rainfalls (Dawson et al. 2009).

Based on the fine-scale modeling, stabilization of the cliff would be the more effective and therefore preferred option to prevent cliff erosion which would include maintaining and restoring vegetation growth on the top of the cliff to increase soil cohesion. Reducing the angle of the slope could help counteract future uncontrolled weathering and sliding. However, this solution requires enough space at the foot as well as at the top of the cliff (Mangor et al. 2017). Waterlogged soil also likely contributes to cliff erosion and risk of collapse, along with rainwater runoff and storm damage (Bosch et al. 2006). Therefore, it may also be appropriate to drain excess water flows during heavy rainfall events with a channel that creates a diversion away from the cliff top. An additional intervention would be to protect the toe of the cliff with revetment. Given the near vertical angle of the cliff face, the most effective interventions are likely to be at the top of the cliff, with revegetation and a diversion channel (Mangor et al. 2017).

\subsubsection{Ecosystem-based approaches}

An alternative to engineered interventions with structures like concrete seawalls are ecosystem-based adaptations or nature-based solutions (NbS) (Chausson et al. 2020). On the basis of the global model results which point to wave energy being the casual factor, $\mathrm{NbS}$ in the coastal zone could include protecting and restoring coral reefs, dunes, mangroves, and saltmarsh. Coastal ecosystems stabilize shorelines by reducing wave energy and trapping sediments (Colls, in IUCN, 2009). However, their deployment is dependent on the local context, including the coastal geomorphology (Chausson et al. 2020). In Port Resolution, mangroves do not naturally occur, but the growth of coastal saltmarsh vegetation could potentially be encouraged to help prevent any undercutting at the base of the cliff (Bosch et al. 2006).

The benefits from the existing ecosystems and natural processes were illustrated by running the coastal process model under scenarios where the reef was removed and the embayment was dredged to increase its utility for anchoring of recreational yachts. The results showed a potential increase in wave height to the shoreline from these interventions adjacent to the road. From this perspective, protecting existing ecosystems can represent a powerful $\mathrm{NbS}$. One approach for reef protection is through establishing well-managed community conservation areas supported by community ranger programs and related capacity building activities (Dawson et al. 2009).

\subsubsection{Limited intervention, maintaining current management options, and managed realignment}

An artificial reef constructed in the embayment could act like a natural protection by dissipating the wave energy and providing some additional protection of the shoreline; these also provide a substrate for marine life provide additional ecosystem service benefits (Reguero et al. 2018). However, during high water levels, especially during storm surge events, the effects of those structures would be limited. 
At the current rate of erosion (Fig. 5), the main road is likely to be threatened in approximately 10 years, with the school building impacted in around 15 years. Our modeling results are equivocal as to whether coastal processes may or may not lead to continued erosion, and maintaining the status quo management provides the benefit of avoiding the costs of engineered solutions. However, this approach leaves the residual risk cost of further cliff erosion and potential sudden catastrophic loss which can be quantified annually. A 10- to 15-year timeframe allows for a reasonable buffer against sudden, large-scale loss of the cliff top. Furthermore, anecdotal evidence suggests sand and coral rubble have, until recently, been constantly removed from the bay, which may have had an impact on the rate of erosion of the cliff. Cessation of this activity therefore may slow the rate of future erosion.

Managed realignment or retreat refers to the relocation of assets landward to accommodate the predicted shoreline recession. Under this intervention, the school buildings would be pre-emptively moved and rebuilt in year 0 , with the road to be realigned in year 10. Managed realignment can significantly reduce the cost of providing a level of protection and maintenance against erosion or flooding. Further cost savings can be made if realignment allows the defensive line to be shortened or completely abandoned (Nicholls et al. 2007).

\subsection{Adaptations options and their cost-benefits}

In addition to the efficacy of an intervention to address the cliff erosion, other factors need to be taken into account when evaluating adaptation options including (a) the design, construction, and maintenance costs; (b) how they affect or are affected by existing policy and planning such as national guidelines and local government spatial zoning; and (c) their social acceptability which reflects local social and cultural norm, needs, and aspirations (Buckwell et al. 2020a). Here we focus on the direct design, construction, and maintenance costs, acknowledging that indirect costs, such as loss of income or nonmarket costs such as loss of community cultural values, were not considered. A descriptive, qualitative comparison between the candidate set of options and detailed costs is provided in Table 2 .

Hard engineering structures can be built from a range of materials including gabion, geotextile, shotcrete, epoxy injection, boulder, and timber. Costs depend significantly on the design and materials used as well as the transportation, construction, and labor costs, along with any plan overlays that need to be considered. The estimated costs of rebuilding the school and realigning the road were obtained from on-site advice and phone-based estimates from reputable suppliers of each (Ware et al. 2020) (Table 2). Also included are estimates of the costs for the $\mathrm{NbS}$ adaptation intervention extrapolated from Buckwell et al (2020b) who estimated Community Conservation Area (CCA) implementation costs on a per hectare per year level. These estimated costs included the development of a community ranger program which is an essential capacity for CCA management practices.

Based on studies from Ferrario et al. (2014), it was found that reef conservation and restoration can be cost-effective for risk reduction and adaptation. They found that reef restoration was always substantially more cost-effective than breakwaters across eight nations considering only coastal defense benefits. This adaptation represents a low cost to develop and implement. 


\section{Discussion}

The global scale model and data pointed to wave energy are the main cause of the eroding cliff face in the Port Resolution embayment. On this basis, a seawall, or groyne, would be an effective adaptation intervention to reduce the risks to school buildings and the adjacent road due to the retreat of the cliff. Costs aside, the finer scale modeling undertaken in this study demonstrated how waves close to the shore are highly influenced by water depths, with wave speed reducing in shallower waters as waves increase in steepness and height. Eventually, the waves slow down drastically and dissipate through breaking. Global data are useful for understanding regional oceanic hydrodynamic processes, but a finer scale model is indispensable for identifying site-specific hazards, associated risks, and costeffective adaptation options. Adaptations to coastal hazards need to be location-specific and cannot necessarily be transferred to another site without understanding local conditions and processes.

The fine scale modeling undertaken in this study has identified that the ongoing erosion at the cliff bordering the school in Port Resolution is not directly caused by high wave energy but is related to a wide range of additional triggering factors, such as local currents, sea levels, seismic activities, temperature variations, and rainfall events. Indeed, while the wave impacts directly affect the base of the cliff, rain mostly impacts the upper region of the cliffs (Young et al. 2021). Both runoff and infiltration drive cliff instability (Bumseng and Kaoh 2018). Cliff failures can occur due to rainfall and groundwater recharge causing gravitational loading and reduced shear strength due to increased pore water pressure (Young et al. 2021). Moisture and water availability (Dietze et al. 2020) and geometry also play a role in cliff instability (Emery and Kuhn 1982).

Identifying effective intervention options is crucial in coastal adaptation as maladaptation can result in cliff failure, as shown in Palma et al. (2020), or in inappropriate resource allocation. In this case, a seawall was constructed at the base of the cliff but the lack of drainage in the seawall has led to the cliff failure. The projected change in the annual total rainfall under RCP 8.5, in 2070, is for a 2\% increase (Australian Bureau of Meteorology and CSIRO 2011) and the frequency and intensity of extreme rainfall events is projected to increase with high confidence. The current 1-20-year daily rainfall is projected to increase by $8 \mathrm{~mm}$ by 2030 for RCP 8.5 and by $40 \mathrm{~mm}$ for RCP 8.5 by 2090 (PACCAP, 2014). This increase adds further stress in the stability of the cliff (Dietze et al. 2020; Young et al. 2021). The impacts of climate change, therefore, may increase rates of cliff retreat as they are connected to specific mechanism, each involving different sea levels, wind, and rainfall thresholds (Brooks et al. 2012). From the results of the local scale model and analysis, we concluded that adaptation options are needed that serve to stabilize the cliff, addressing geotechnical factors including through revegetation (Chausson et al. 2020).

To evaluate the adaptation options, it was necessary to evaluate the cost benefits of interventions that could address the risks to valued assets from the identified coastal hazard using the fine scale model results and local data. Based on the low wave energy at the toe of the cliff along with the costs and the uncertainty of the long-term viability of the engineering structures, more cost-effective use existing natural defenses and pre-emptively moving school buildings and later realigning the road. While engineering options would contribute to the stabilization of the cliff, the fact that Port Resolution is not currently subject to major modern developments and is exposed to other uncontrollable and unpredictable hazards including earthquake and landslides which can trigger the cliff's stability, engineering options are not as cost-effective compared to $\mathrm{NbS}$. These results agree with 
the study of Moore et al. (2017) which showed that where the coastline continued to retreat due to a combination of marine erosion and associated landslides, seawalls do not prevent shoreline retreat or protection from extensive damage.

In Port Resolution, local actions to reinforce the base of the cliff, taken at a considerably lower cost, could be considered to avoid landslide and further cliff erosion. Reinforcing the cliff zone with vegetation is also likely to slow down erosion processes due to excess of rainfall or seismic activity. Coastal landslides have been identified in many places as a consequence of a combination of cliff toe recession and geotechnical processes within the cliff slope (Dawson et al. 2009). In Port Resolution, the high ash content of clifftop soil makes it porous and heavy following rainfall events. The stabilization of the cliff could include woody vegetation on the top using their deep roots to reduce soil erosion and landslide risk or changing the slope geometry. Several projects over the world show effective nature-based coastal defense strategies (Morris et al. 2019). In Bumseng and Kaoh (2018), the use of natural vegetation was shown to successfully prevent erosion by slowly stopping the soil from being washed away by rains into the sea. Vegetation could also play a beneficial role at the toe of the cliff; saltmarsh plantings and stones placed at the base of the cliff could provide enhanced protection, as shown in Bosch et al. (2006). NbS using vegetation can easily adapt to other climate change drivers, including sea level and wave storminess (Duarte et al. 2013). NbS may be a cost-effective alternative to artificial structures, with lower maintenance costs than artificial structures that need to be rebuilt when damaged (Morris et al. 2019). Indeed, relocation of the school buildings and a realignment of the current unsealed road are technically feasible but not without considerable costs. With a growing population (Vanuatu National Statistics Office 2021), a larger school complex will also be needed at some point in the near future, so there is an opportunity for modifying the services available to the community whilst removing the building from short-term risk. The relatively low cost of building reconstruction makes "do nothing," "managed realignment," and "community conservation area implementation" options extremely attractive compared to the "hold the line" options. In Port Resolution, managing the retreat of the school and the limitation of the development on the top of the cliff would be the most beneficial strategy in terms of costs and avoiding the coastal erosion hazard.

This paper addressed one of the challenges that SIDS face in terms of generating accurate assessments of hazards at a local scale for adaptation planning. Our study benefited from the knowledge provided by the local community of what were coastal impacts of concern (here, the unstable cliff face) as well as being best placed to identify which adaptation options are socially acceptable (Buckwell et al. 2019). We were able to calibrate a hydrodynamic model using local scale data generated by the authors and other researchers working in the area. However, this kind of modeling is only possible if such data are available, and there is present the technical capacity. Unfortunately, SIDS governments can lack the capacity to calibrate and apply these kinds of numerical models, particularly at the scale and intensity required. While this has led some to conclude that locally appropriate adaptation appraisal processes - and consideration of options that don't demand overseas practitioners or consultants - will likely be more effective and sustainable (McNamara et al. 2020), it also reinforces the conclusion that in the absence of accurate assessment, no-regrets options, such as managed realignment or $\mathrm{NbS}$ remain superior to projects with a higher risk of maladaptation (Piggott-McKellar et al. 2019). We also emphasize the importance of considering costs of adaptation (cost-effectiveness) in terms of lifecycle costs. Investments in often lengthy evidence-based project planning have been shown to reduce the projected lifecycle cost of projects or demonstrate a considerably greater return on investment on a longer time horizon (Buckwell, et al. 2019). We also highlight the 
non-binary nature of the decision-making space and are optimistic for the SIDS community's capability of engaging with the science, given the right support (Faivre et al. 2020). Therefore, if the benefits of more accurate hazard analysis and adaptation assessment are to be realized, then a significant increase in local capacity building for modeling is needed for SIDS, including funding that increases the ability of local universities as the enduring education and training institutions in these regions.

While the modeling outlined in this paper represents a significant advance in knowledge for a data-scarce region, it is also important that ongoing, "ground-truthing" surveys are undertaken, to continue to build the knowledge base and update estimates of ongoing erosional processes. This physical survey risk assessment should be coupled with ongoing community engagement to learn and share views of risks and community viewpoints around adaptation responses and acceptable interventions. Encouraging the local people to survey the shoreline changes over time would empower the local community to understand risks and to make informed decisions.

Beyond an engineered solution to cliff erosion risks, some actions could focus on reducing the coastal hazard exposure of the community. This could take the form of a coastal hazard assessment with community engagement to inform and empower the local people to determine the best course of action (Alves et al. 2020). For example, successful projects engaging communities with interactive platforms have increased communication between scientists, planners, and indigenous groups (Hutton and Allen 2020). Multilevel inputs as well as scientific, governance, operational, and communities are required (Alves et al. 2020) and addressing transdisciplinary issues to enhance adaptive conditions and to identify change over time and space. In addition, it has been demonstrated that traditional knowledge witnessing changes reinforce the monitoring (Hutton and Allen 2020).

The results from this research are helping inform local adaptation decision-making through an ongoing collaboration with the Tafea Provincial Government and the Tanna Communities (Buckwell et al. 2020a, b). Sharing knowledge of the risks associated with heavy rainfall events that may trigger cliff collapse can further safeguard the community. Actions supporting decision-making around where buildings should be placed can reduce the exposure to cliff collapse hazards in an ongoing way. In this sense, particularly in light of the future vulnerability of the school from shoreline retreat, it may be necessary for the community to consider managed retreat or hazard-sensitive planning as part of an ongoing adaptation plan. In some cases, relocation of critical infrastructure like schools and churches from hazard-prone areas is the more viable option than high cost and low return approaches to reduce the magnitude of the hazards themselves. Climate change and its impacts on coastal hazards need to be integrated into coastal planning, with high-risk areas such as the cliff studied in this paper, zoned to ensure that only appropriate and resilient land use and developments occur. Community level decision-making can be supported by providing more accurate assessments of climate-related risks, coastal hazards, and efficacy and costs of adaptation options. Adaptation is most effective when information is shared by local communities and provincial and national planners, with communities benefitting from early warning systems, climate services, and information provided through media communication (Klock and Nunn 2019; Webber 2015).

\subsection{Limitations of this study}

The lack of local data was the major limitation faced by this study. In addition, the lack of built structures and the extensive forest and subsistence garden vegetation cover over the 
land around Port Resolution Bay made the geo-rectification of satellites images difficult. For example, the vegetation at the top of the cliff obscured in places the shoreline position. The predicted rates of shoreline erosion ( $0.3 \mathrm{~m} /$ year over the period of 2006-2020) could be overestimated due to error associated with the use of the satellite data but also as the result of the relatively short time series available for this area. Water levels which affect the amount of erosion were not considered here and are influenced by many factors including the seasons, tides, storms, seiches, drought, and the general rise of global sea level (Bosch et al. 2006). Tropical Cyclone Pam, a 100-year event, occurred in 2015, and this may have increased the apparent rate of shoreline retreat. However, as future climate projections for the region suggest that extreme climate events are like to become more intense (Australian Bureau of Meteorology and CSIRO 2011), our calculated rates of erosion may well be within the range that will be experienced over the coming decades. While the best available bathymetric and topographic data were used, additional validation would be warranted should improved data become available. Finally, we note that the relative sea-level rise rate for Tanna Island is not clear due to the volcanic and tectonic activity. Yenkahahe dome in Tanna Island has exhibited an uplift rate over the past 1000 years of around $156 \mathrm{~mm} /$ $\mathrm{yr}^{-1}$ on average (Chen et al. 1995), which is well above the sea-level trend in Vanuatu of $6 \mathrm{~mm} \mathrm{yr}^{-1}$. Encouraging and enabling ongoing locally scaled data survey campaigns in this region on a regular basis is therefore particularly important in the context of the tectonic uplift processes evident on the island (Brothelande et al. 2016). We also note that policies and regulations which must be considered for adaptation planning were outside the scope of this study and therefore not addressed here.

\section{Conclusion}

Strategies and options for adaptation need to be based on a sufficiently accurate identification of coastal hazards and consideration of the costs and benefits for interventions that could mitigate the associated risks to valued assets. Reliance on models driven by global data outputs alone resulted in a different understanding of the hazard and the adaptation options, compared with models using local data. The global models pointed to adaptations that would reduce wave energy in the bay at the foot of the cliff, while the local models revealed a more nuanced understanding of the process of cliff erosion in Port Resolution, supporting adaptation options that would stabilize the cliff and remove valued assets from exposure to the eroding cliff hazard. Adaptations based on the global model were not only more expensive but likely ineffective in preventing ongoing cliff erosion and landslides. The adaptation options arising from the more accurate diagnosis of the hazard provided by the local model - including the NbS of revegetation at the top of the cliff and the "managed realignment" of schools buildings and the unsealed road - are likely to be the preferred adaptation options with a better cost-benefit outcomes in comparison with "hold the line" options. This result may well be relevant for coastal risk assessment and adaptation planning in other small island developing country communities. The long-term success of adapting to climate change relies on the involvement of community and implementation of adaptation strategies together.

Acknowledgements This research was undertaken through an MOU with the Tafea Provincial Government and under a research agreement with the Vanuatu National Cultural Centre representing the Government of the Republic of Vanuatu and the local community. We are grateful to the Port Resolution community for their permission to undertake this research and for their cooperation, generosity, humor, and hospitality. 
In particular, we thank Alan Dan, our Tanna Kastom advisor and community liaison, and Mr. Mark Filmer for his contribution in proofreading this manuscript. The research was also supported by a grant to Griffith University from a charitable organization which neither seeks nor permits publicity for its efforts. The donor had no influence on any aspect of the design, execution, or documentation of this research.

Author contribution Faivre, Tomlinson, and Mackay led the conception and design of the manuscript. Buckwell, Ware, and Hadwen did the economic study part and led the interviews in Tanna. Faivre, Shaeri, and Tomlinson led data analysis and interpretation. Hadwen co-drafted the Methods section manuscript with Faivre. Faivre led draft revisions, with all authors contributing to the revision process.

Funding Open Access funding enabled and organized by CAUL and its Member Institutions. The research was supported by a grant to Griffith University from a private charitable trust that wishes to remain anonymous. The donor had no influence on any aspect of the design, execution, or documentation of this research.

Data availability Detailed outputs from the numerical model described in the paper including wave energy outputs with adaptation options such as groynes, reef and dredge are available upon request to the authors.

Code availability Not applicable.

\section{Declarations}

Ethics approval Not applicable.

Consent to participate This research was undertaken through an MOU with the Tafea Provincial Government and under a research agreement with the Vanuatu National Cultural Centre representing the Government of the Republic of Vanuatu and the local community.

Consent for publication All authors give their consent for the publication in the Climatic Change journal.

Conflicts of interest The authors declare no competing interests.

Open Access This article is licensed under a Creative Commons Attribution 4.0 International License, which permits use, sharing, adaptation, distribution and reproduction in any medium or format, as long as you give appropriate credit to the original author(s) and the source, provide a link to the Creative Commons licence, and indicate if changes were made. The images or other third party material in this article are included in the article's Creative Commons licence, unless indicated otherwise in a credit line to the material. If material is not included in the article's Creative Commons licence and your intended use is not permitted by statutory regulation or exceeds the permitted use, you will need to obtain permission directly from the copyright holder. To view a copy of this licence, visit http://creativecommons.org/licenses/by/4.0/.

\section{References}

Alves B, Angnuureng B, Morand P, Almar R (2020) A review on coastal erosion and flooding risks and best management practices in West Africa: what has been done and should be done. J Coast Conserv 24:38. https://doi.org/10.1007/s11852-020-00755-7

Australian Bureau of Meteorology and CSIRO (2011) Climate change in the pacific: scientific assessment and New research. Volume 1: regional overview. Volume 2: Country Reports

Barnett J, Campbell J (2010) Climate Change and Small Island States. Power, Knowledge and the South Pacific. London: Earthscan

Boateng I (2012) An assessment of the physical impacts of sea-level rise and coastal adaptation: a case study of the eastern coast of Ghana. Clim Chang 114:273-293. https://doi.org/10.1007/s10584-011-0394-0

Bosch J, Foley C, Lipinski L, McCarty C, McNamara J, Naimaster A, Raphael A, Yang A, Baldwin A, Maryland Department of the Environment (2006) Shore erosion control guidelines; marsh creation. Maryland Department of the Environment Wetlands and Waterways Program 
Brooks SM, Spencer T, Boreham S (2012) Deriving mechanisms and thresholds for cliff retreat in softrock cliffs under changing climates: rapidly retreating cliffs of the Suffolk coast, UK. Geomorphology 153:48-60

Brothelande E, Lénat JF, Normier A, Bacri C, Peltier A, Paris R et al (2016) Insights into the evolution of the Yenkahe resurgent dome (Siwi caldera, Tanna Island, Vanuatu) inferred from aerial high-resolution photogrammetry. J Volcanol Geother Res 322:212-224. https://doi.org/10.1016/j.jvolgeores.2015.04. 006

Buckwell A, Ware D, Fleming C, Smart JCR, Mackey B, Nalau J, Dan A (2019) Social benefit cost analysis of ecosystem-based climate change adaptations: a community-level case study in Tanna Island Vanuatu. J Clim Dev 12(6):495-510

Buckwell AJ, Fleming C, Smart JCR, Ware D, Mackey B (2020a) Challenges and sensitivities in assessing total ecosystem service values: lessons from Vanuatu for the pacific. J Environ Dev. https://doi.org/10. $1177 / 1070496520937033$

Buckwell A, Fleming C, Muurmans M, Smart J, Mackey B (2020b) Revealing the dominant discourses of stakeholders towards natural resource management in Port Resolution, Vanuatu, using Q-method. Ecol Econ 177:106781. https://doi.org/10.1016/j.ecolecon.2020.106781

Bumseng G, Kaoh, P (2018) A sustainable solution to soil erosion in Vanuatu. Experience capitalization, resilience and productivity in the pacific. Experience Capitalization Series 7. Wageningen: CTA:47-51

Chausson A, Turner B, Seddon D, Chabaneix N, Girardin CAJ, Kapos V, Key I, Roe D, Smith A, Woroniecki S, Seddon N (2020) Mapping the effectiveness of nature-based solutions for climate change adaptation. Glob Change Biol 26(11):6134-6155

Chen JK, Taylor FW, Edwards RL, Chang H, Burr GS (1995) Recent emerged reef terraces of yenkahe resurgent block, tanna, Vanuatu: implications for volcanic, landslide and tsunami hazards. J Geol 103(5):577-590

Google Earth Pro 7.3.3.7786 (2020) CNES/Airbus Images

Colls A, Ash N, Ikkala N (2009) Ecosystem-based adaptation: a natural response to climate change. IUCN, Gland

Dawson RJ, Dickson ME, Nicholls RJ et al (2009) Integrated analysis of risks of coastal flooding and cliff erosion under scenarios of long term change. Clim Change 95:249-288. https://doi.org/10.1007/ s10584-008-9532-8

Deltares (2018) Delft3D-FLOW User Manual, Hydro-morphodynamics, Version 4.04.01. http://content.oss. deltares.nl/delft3d/manuals/Delft3D-FLOW_User_Manual.pdf

DHI (2020) Mike 21, Hydrodynamic module user guide

Dietze M, Cook KL, Illien L, Rach O, Puffpaff S, Stodian I, Hovius N (2020) Impact of nested moisture cycles on coastal chalk cliff failure revealed by multiseasonal seismic and topographic surveys. J Geophys Res Earth Surf 125:8p.e2019JF005487

Donner SD, Webber S (2014) Obstacles to climate change adaptation decisions: a case study of sea-level rise and coastal protection measures in Kiribati. Sustain Sci 9:331-345. https://doi.org/10.1007/ s1 1625-014-0242-z

Duarte C, Losada I, Hendriks I et al (2013) The role of coastal plant communities for climate change mitigation and adaptation. Nature Clim Change 3:961-968. https://doi.org/10.1038/nclimate1970

Emery KO, Kuhn GG (1982) Sea cliffs: their processes, profiles, and classification. Geol Soc Am Bull 93(7):644-654

ESRI, Digital Globe. ArcGIS Desktop: Release 10.4.1 (2018) Environmental systems research institute: Redlands

Faivre G, Vieira da Silva G, Aimbie J, Ware D, Tomlinson R, Mackey B, Hong Z (2020) Coastal processes within a coral reef lagoon system: Erakor lagoon, Efate Island, Vanuatu. In: Malvárez, G. and Navas, F. (eds.), Global Coastal Issues of 2020. J Coast Res 95:1427-1432 (Coconut Creek (Florida), ISSN 0749-0208)

Ferrario F, Beck M, Storlazzi C et al (2014) The effectiveness of coral reefs for coastal hazard risk reduction and adaptation. Nat Commun 5:3794. https://doi.org/10.1038/ncomms4794

Frankland R, Hardwick L, Watkin S (2012) Climate change adaptation in a small Pacific Island nation. Proceedings of the Institution of Civil Engineers-Civil Engineering 165(6):46-51. https://doi.org/10.1680/ cien. 11.00054

GEBCO Bathymetric Compilation Group 2019 (2019). The GEBCO_2019 Grid - a continuous terrain model of the global oceans and land.British Oceanographic Data Centre, National Oceanography Centre, NERC, UK. 10/c33m

Himmelstoss EA, Henderson RE, Kratzmann MG, Farris AS (2018) Digital shoreline analysis system (DSAS) version 5.0 user guide: U.S. Geological Survey Open-File Report 2018-1179, 110 p 
Holland G, Belanger JI, Fritz A (2010) A revised model for radial profiles of hurricane winds. Mon Weather Rev 38:4393-44

Hutton NS, Allen TR (2020) The role of traditional knowledge in coastal adaptation priorities: the pamunkey indian reservation. J Water 12(12):3548

IPCC (2019) IPCC Special Report on the Ocean and Cryosphere in a Changing Climate [H.-O. Pörtner, D.C. Roberts, V. Masson-Delmotte, P. Zhai, M. Tignor, E. Poloczanska, K. Mintenbeck, A. Alegría, M. Nicolai, A. Okem, J. Petzold, B. Rama, N.M. Weyer (eds.)]. In press. Google Earth Pro 7.3.3.7786 (2020) CNES/Airbus Images

Klock C, Nunn PD (2019) Adaptation to vlimate change in small island developing states: a systematic literature review of academic research. J Environ Dev

Mangor K, Dronen NK., Kaergaard KH, and Kristensen NE (2017) Shoreline management guidelines. DHI. https:www.dhigroup.com/marinewater/ebook-shoreline-management-guidelines

McNamara KE, Clissold R, Westoby R et al (2020) An assessment of community-based adaptation initiatives in the Pacific Islands. Nat Clim Chang 10:628-639. https://doi.org/10.1038/s41558-020-0813-1

Moore R, Davis G, Stannard M, Browning N (2017) Stabilising Lyme Regis - A strategic approach. Proc Inst Civil Eng 170(2):63-70

Morris R, Strain EMA, Konlechner TM, Fest BJ, Kennedy DM, Arndt SK, Swearer SE (2019) Developing a nature-based coastal defence strategy for Australia. Aust J Civ Eng 17(2):167-176

Nicholls RJ, Cooper N and Townend I.H (2007) The management of coastal flooding and erosion in Thorne, C.R. et al. (Eds.). Future Flood and Coastal Erosion Risks. London: Thomas Telford, 392-413

Oppenheimer M, Glavovic BC, Hinkel J, van de Wal R, Magnan AK, Abd-Elgawad A, Cai R, CifuentesJara M, DeConto RM, Ghosh T, Hay J, Isla F, Marzeion B, Meyssignac B, and Sebesvari Z (2019) Sea level rise and implications for Low-lying islands, coasts and communities. In: Pörtner H-O, Roberts DC, Masson-Delmotte V, Zhai P, Tignor M, PoloczanskaE, Mintenbeck K, Alegría A, Nicolai M, Okem A, Petzold J, Rama B, Weyer NM. IPCC Special Report on the Ocean and Cryosphere in a Changing Climate. In press

Palma A, Garrill R, Brookk MS, Richards N, Tunnicliffe J (2020) Reactivation of coastal landsliding at Sunkist Bay, Auckland, following ex-Tropical Cyclone Debbie, 5 April 2017. Landslides 17:2659-2669

Piggott-McKellar AE, McNamara KE, Nunn PD, Sekinini ST (2019) Moving people in a changing climate: lessons from two case studies in Fiji. Soc Sci 8(5):133

Piggott-McKellar AE, Nunn PD, McNamara KE, Sekinini ST (2020) Dam(n) seawalls: a case of climate change maladaptation in Fiji. In: Leal Filho W. (eds) managing climate change adaptation in the pacific region. Climate Change Management. Springer, Cham

Reguero BG, Beck MW, Agostini VN, Kramer P, Hancock B (2018) Coral reefs for coastal protection: a new methodological approach and engineering case study in Grenada. J Environ Manage 210:146-161

Sanford LP, Gao J (2018) Influences of wave climate and Sea level on shoreline erosion rates in the Maryland Chesapeake Bay. Estuaries and Coasts 41:19-37. https://doi.org/10.1007/s12237-017-0257-7

SRTM, 2020. https://www.usgs.gov/centers/eros/science/usgs-eros-archive-digital-elevation-shuttle-radartopography-mission-srtm-non?qt-science_center_objects=0\#qt-science_center_objects

Tolman HL (2009) User manual and system documentation of WAVEWATCH III ${ }^{\mathrm{TM}}$ version 3.14. NOAA / NWS / NCEP / MMAB Technical Note 276, 194 pp + Appendices

Tomlinson R, Angus Jackson L (2019) Seawalls for coastal protection and climate change adaptation: a case study from the Gold Coast. In: Mathew J., Lim C., Ma L., Sands D., Cholette M., Borghesani P. (eds) Asset intelligence through integration and interoperability and contemporary vibration engineering technologies. Lecture Notes in Mechanical Engineering. Springer, Cham. https://doi.org/10.1007/ 978-3-319-95711-1_58

UK Hydrographic Office (2017). https://www.gov.uk/government/organisations/uk-hydrographic-office Vaunatu Government, 2019. National policy on climate change and disaster-induced displacement. http://extwprlegs1.fao.org/docs/pdf/van182464.pdf

Vanuatu National Statistics Office (2021) https:/vnso.gov.vu/index.php/en/census-and-surveys/census/ census-2020.

Vitousek S, Barnard PL, Fletcher CH, Frazer CH, Erikson L, Storlazzi CD (2017) Doubling of coastal flooding frequency within decades due to sea-level rise. Sci Rep 7:1399. https://doi.org/10.1038/ s41598-017-01362-7

Ware D, Buckwell A, Tomlinson R, Foxwell Norton K, Lazarow N (2020) Using historical responses to shoreline change on Australia's Gold Coast to estimate costs of coastal adaptation to sea level rise. J Marine Sci Eng 8(6):380. https://doi.org/10.3390/jmse8060380

Webber S (2015) Mobile adaptation and sticky experiments: circulating best practices and lessons learned in climate change adaptation. Geograp Res 
Williams T, Rangel-Buitrago N, Pranzini E, Anfuso G (2018) The management of coastal erosion. Ocean Coast Manag 156:4-20

Young AP, Guza RT, Matsumoto H, Merrifield MA, O'Reilly WC, Swirad ZM (2021) Three years of weekly observations of coastal cliff erosion by waves and rainfall. J Geomorphol 375(15):107545

Publisher's note Springer Nature remains neutral with regard to jurisdictional claims in published maps and institutional affiliations. 